\title{
Literature Review of Load Balancing Routing Protocols in MANET
}

\author{
Mahdi Abdulkader Salem \\ Department of Computer Sciences \& Information \\ Technology Sam Higginbotom Institute of \\ Agriculture, Technology \& Sciences Allahabad \\ India
}

\author{
Ragav Yadav, PhD \\ Department of Computer \\ Science \& Information \\ Technology Sam Higginbotom Institute of \\ Agriculture, Technology \& sciences Allahabad \\ India
}

\begin{abstract}
Mobile Ad hoc Network (MANET) is nothing but group of radio devices communicating with each other without using any physical infrastructure. MANET is widely used in day to day life applications, hence it is required that such network should perform efficiently. Efficiency of MANET is mainly depends on use of routing protocols. The efficiency of routing protocol is evaluated in terms of different Quality of Service (QoS) metrics. Achieving good QoS in MANET is more challenging as compared to wired networks due to mobile network, limited battery and no centralized control. Therefore different MANET routing protocols are introduced by various authors with goal of achieving efficient load balancing and QoS. In recent time, there are many new routing protocols were introduced those are presented for improving QoS. The aim of this paper is to give introduction to different MANET routing protocols and categories. Challenges and issues of achieving QoS in MANET then discussed different performance metrics which decides the QoS of MANET routing protocols. Finally presented different Load balancing routing protocols presented along with their merits and demerits are discussed.
\end{abstract}

\section{Keywords}

MANET, Reactive, Routing protocols, Hybrid, QoS, and Load Balancing, Proactive.

\section{INTRODUCTION}

The concept of MANET using any cable, infrastructures, Architecture Group of wireless mobile nodes without nothing. This network every mobile node acts peer or both work as packet routing (forwarding) to send and receive packets. MANET does not require centralized administration or network infrastructure such as base stations or access points [1] fixed. A MANET mobile users that reasonably slow wireless link is an autonomous group of dialog. Because nodes are mobile network topology quickly and unpredictably over time, May vary. Such a network can operate in a standalone fashion, or can be connected to the larger Internet. MANET bandwidth-constrained, variable capacity is near certain features like links, energy operations, limited physical security, dynamic network topology constrained, and often routing updates [2].

Communication is held by MANET which routing protocol is the key. There are several routing protocols for MANET are presented. In this paper discussed the routing protocol and comparative study on them are taking different MANET review. In this paper here disable unicast responses to routing protocols are mainly concentrated. In the following sections, section II classification of MANET routing protocols in different categories and discussing about. Section III, section

IV summary disable unicast responses to routing protocol over active, reactive and hybrid routing protocols to review [2].

\section{ROUTING PROTOCOLS IN MANET}

As the concept know about MANET, architecture or network topology which changes time by time out randomly and is not fixed. This network architecture, a dedicated server with a dedicated router, and also is not a dedicated access points. That's why MANET and temporary network change without any infrastructure network which consists of mobile nodes. Application of the following key points are regarded as MANET

1. Most demanded in Military areas.

2. Search and rescue

3. During the transportation for vehicle-to-vehicle mobile communication is need such networks.

4. For the meeting rooms, conference, airports here need the temporary networks for the immediate communications.

5. Other personal network areas to which the smart cards, cell phones \& mobile, laptops, etc. connected need such mechanisms.

Mobile nodes when otherwise they lived in each other's radio waves directly to each other in the intermediate node communicating to each mobile node in the destination mobile node router route [10] in the next mobile node to forward the information to the source for mobile node functions to forward the information to access is needed.

Protocols such as RIP, OSPF, etc. which is used in wired networks but they direct the following reasons why MANET networks can be used to:

(1) uni-directional links between nodes may be present in.

(2) Eligible for communication between two nodes in a path is a plus.

The bandwidth consumption, power consumption leads to (3) are routing update often enough.

(4) As compared to the topology changes frequently, the routing fabric slow coverage.

Thus a lot of research design and mobile ad hoc network routing algorithms are used to implement and that's why MANET routing protocols are divided into the following parts:

(1) Disable unicast responses to routing protocols 
A topology-based routing protocols.

- Dynamic routing protocols - OLSR, FSR etc.

- Reactive routing protocol-AODV, DSR

- Hybrid routing protocol-ZRP

B Geographical-based routing protocols.

(2) Multicast routing protocol-MAODV (which are not considered during paper) etc.

(3) Broadcasting algorithms (this also do not consider this letter)

All the above categories even though several routing protocols for MANET routing mechanisms is available, but a protocol covering cant or MANET scenarios and applications of all kinds of routing protocol traffics, MANET. For example wide band, with high mobility, small-scale network protocols to proactive category are more suitable for such networks. On the other hand, on a large scale with low mobility narrow band range of the big network reactive routing protocols are most appropriate for the Protocol from the network. Mobile network to achieve peer nodes if broadcast to resort and they are moving in MANET networks soon. Finally, one must conclude that each routing protocol in MANET networks, using it and using it to loss its benefits, and most importantly they applications [10] were chosen on the basis of on. And therefore the Routing Protocol's requirements and are selected on the configuration of network applications. After MANET routing protocol hierarchy of Figure 1 are shown.

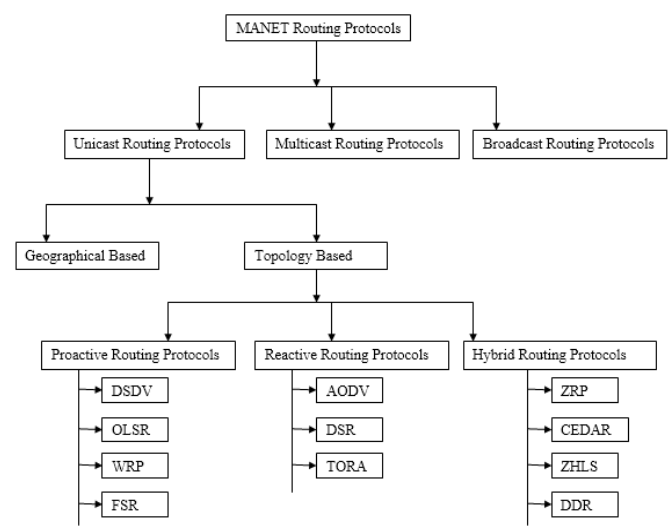

Figure 1: Ad hoc Network Routing Protocols Classification

In the next section III discussed Unicast Routing protocols in details.

\section{UNICAST ROUTING PROTOCOLS}

Many require MANET applications disable unicast responses to network communication and therefore here need to place in the routing disable unicast responses to communication protocols. This application requires that successful originator node over IP packets with destination nodes in the MANET as data transmission network layer. Forwarding process is easy and simple, such as routing protocols, which relay packet forwarding node, it is up to the current routing table in order of the destination node. If the routing table is the destination path which in order to found in long beach, Forwarding mechanism and hop count increases to the next node forwards accordingly. Routing protocols which are up to and to offset the effects that mobility [1] [2] introduced by all kinds of plans that the numbers used are numerous.

\subsection{Proactive Unicast Routing Protocols}

OSPF and RIP routing protocols traditionally are proactive disable unicast responses to a best example of. Calculate the source node to the destination node with the smallest, the network topology is often broadcast in such a protocol for updating is necessary. Of the shortest path calculation consumes lots of network bandwidth. Even if they are used frequently in the spinal cord in MANET networks directly wired network and mobile ad-hoc network differences between cannot use due to the fact.

\subsubsection{OLSR- Optimized Link State Routing Protocol}

OLSR (optimized link state routing) Protocol in MANET networks [7] the main objective of efficient routing mechanism had to offer. This Protocol is called multipoint relaying MPR technique as in floods topology broadcast packet is meant to reduce the system was based on. OLSR Protocol work to detailed process consists of:

(1) Each node network which is from time to time on the next node information in the Hello messages broadcasting on the network. Every node broadcasts Hello messages that one-hop neighbor information are from time to time. Hello neighbor are not forwarded by message messages TTL because nodes 1. Each node of local topology information Hello messages [7] is.

(2) Based on the local information of the topology, which neighbors MPR nodes relaying to multipoint means to act as the set of all nodes are nodes which are termed as selector chooses. These nodes then Hello messages are specified from time to time.

There are two types of role of MPR nodes:

The selector forwarded packets or node I) broadcast when, only nodes which will forward such packets MRP selector node sends;

II) Selector node list periodically by all nodes in the MANET MRP selector node maximum retail price is broadcasted using the flood of technology. The fact is that every node in the network knows how reached the other node that was using the MRP node.

\section{Advantages of OLSR}

1) Broadcasting information existing topology this Protocol reduces the multiple prasupti.

Link state routing protocols 2) broadcasting more network bandwidth is limited compared to the size of the packet in this case saved.

(3) from the source node to the destination node Dijkastra's algorithm \& shortest path with each node in the network using the global topology information that is stored and updated frequently is possible which is calculated by using the.

\subsubsection{FSR: Fisheye State Routing Protocol}

It has to do with a more active routing protocol network with high levels of mobility throughout MANET large-scale mobile ad hoc networks is proposed. Fish eye fisheye state routing name in which the picture object when the object moves farther away from the fish eye high resolution, with fish-eye decreases near the same resolution becomes fish becomes the property of one came from. Fish eye the same mechanism which need to know the source of information is the way that the arrival of the destination node to which to direct toward FSR Protocol was adopted. Packet will be 
rectified by all intermediate nodes movement. The following points are of the FSR will describe functions:

(1) In this case, is divided into different areas that all nodes in the network with specific nodes in the network depend on other nodes of the distances. Such areas as specific scopes are node. Depending on the distance from the specific node within the scope of the inner and outer scopes [5] [6] [7] [8] [9] as are divided into two types.

(2) Frequently updated links to all your neighbors are broadcasted to the State, but the rest of the inner scope nodes routing entries are sent with the highest frequency of low frequency, they are sent routing entries that the routing entries such as nodes for different frequencies at different scopes related to relate. The fact that nodes that are always around and more precise link would receive periodic updates as a result of which the nodes are up who will receive less accurate. With regard to the link state information updates are not filled with MANET's across the network, but which are exchanged which have resulted in the discovery of nodes neighboring node in between.

\section{Advantages}

The source of the information he needs in a way that is away from it to reach the destination node to wings scenario, the source node before the most recent information about link to calculate the shortest path does not exist. Thus the information packet from the source node to the destination using the first approach toward the inner scope and therefore increases the accuracy of the path and finally the packet to the destination node come on. This protocol increases the overhead traffic route which is reduced by only information from time to time make further link state propagation.

\subsubsection{TBRPF: Topology Broadcast Based on Reverse-Path Forwarding Routing Protocol}

One of the more active routing protocol for MANET networks aimed at mobile nodes and high mobility hundreds was proposed. Protocol in each node maintains a partial information about the network topology. When any node in the network wants to communicate to other nodes, it shorted the path by Dijkastra's algorithm, the destination node's minimum spanning tree networks [5] [6] [7] [8] [9] is calculated using the need to access. But such increases in the case which is less overhead by routing the following optimization techniques:

(1) Hello messages which gets periodic differential and all exchanged between neighboring nodes. Hello messages, which is smaller than the size of the OLSR Protocol occurred in neighboring status message updates.

(2) Pass the source nodes only spanning tree nodes are broadcast. It's more to roust MANET network every node instead may choose to broadcast the whole source tree.

(3) If it is possible then Hello message relates to add updates in the topology.

Thus all discussion related to proactive Protocol thereto such as OLSR and TBRPF, FSR, all applications are used in various scenarios and applications depends on the scope of conclude. In the table below, compared to these protocols is presented for different characteristics.

\subsubsection{Comparison of Proactive Routing Protocols}

Following table 1 is showing the comparative study for above discussed three proactive routing protocols.
Table 1: Comparative Study of Proactive Routing Protocols

\begin{tabular}{|c|c|c|c|}
\hline & OLSR & FSR & TBRPF \\
\hline Scope & $\begin{array}{l}\text { Large and } \\
\text { dense } \\
\text { MANETs }\end{array}$ & $\begin{array}{l}\text { Large scale } \\
\text { MANETs } \\
\text { with high } \\
\text { mobility }\end{array}$ & $\begin{array}{l}\text { MANETs } \\
\text { with } \\
\text { hundreds of } \\
\text { nodes and } \\
\text { high } \\
\text { mobility }\end{array}$ \\
\hline $\begin{array}{l}\text { Network } \\
\text { organization }\end{array}$ & Flat & Hierarchical & Flat \\
\hline $\begin{array}{l}\text { Neighbor } \\
\text { detection }\end{array}$ & $\begin{array}{l}\text { Periodical } \\
\text { HELLO } \\
\text { messages }\end{array}$ & $\begin{array}{l}\text { Periodical } \\
\text { link state } \\
\text { updates }\end{array}$ & $\begin{array}{l}\text { Differential } \\
\text { HELLO } \\
\text { messages }\end{array}$ \\
\hline $\begin{array}{l}\text { Optimized } \\
\text { broadcast }\end{array}$ & $\begin{array}{l}\text { Multipoint } \\
\text { relaying }\end{array}$ & $\begin{array}{l}\text { Combined } \\
\text { with } \\
\text { neighbor } \\
\text { detection }\end{array}$ & $\begin{array}{l}\text { Combined } \\
\text { with } \\
\text { HELLO } \\
\text { messages }\end{array}$ \\
\hline $\begin{array}{l}\text { Broadcast } \\
\text { information }\end{array}$ & $\begin{array}{l}\text { MPR } \\
\text { selector list }\end{array}$ & $\begin{array}{ll}\text { Link } & \text { state } \\
\text { update } & \end{array}$ & $\begin{array}{l}\text { (Partial) } \\
\text { spanning } \\
\text { tree }\end{array}$ \\
\hline $\begin{array}{l}\text { Route } \\
\text { freshness }\end{array}$ & Up-to-date & $\begin{array}{l}\text { May be not } \\
\text { up-to-date }\end{array}$ & Up-to-date \\
\hline
\end{tabular}

\subsection{Reactive Unicast Routing Protocols}

Those two major routing protocols under this category often AODV and DSR as their benefits are used in many applications because of it. Global network topology every node and frequently updated MANET's need as dynamic and distributed nature has stored topology information. Cases consumed more bandwidth which is a waste of bandwidth in most of the time is updated in the expired link States as upgrade related, first to make use of such information link [10] with regard to.

Thus, a reactive routing protocol comes here and those who are working in the following two parts:

(1) Path discovery: as know wired network source node to an existing wired network broadcasting ARP packets to all nodes in the request packet as any node before you send any information. ARP request packet using the source nodes is information about Mac addresses. The point here is that discovery works except the IP layer over root path used to search for the same mechanism. Route search looks almost the same, but it works in the IP layer and also in relation to the transmission of information from the source category nodes. If the source side is not getting any route to destination in the source node MANET the way to find out and to reach the destination network in route discovery packet broadcast between all mobile nodes. Intermediate nodes along the path to the next node in [10] route discovery packet forwarding.

(2) Road maintenance: after searching more than of the source node and the destination node was to figure out which middle passage, the next step is to start the message delivery destination, still working to maintain a path mechanism referred to as the maintenance of the route. Route maintenance because in MANET nodes do not move freely to determine the validity of the check. If the transmission failed 
because of some reason to get links, Finding new paths to the source node to the destination route again discovery mechanism [11] [12] [13] started out towards. Reactive routing protocols from which MANET DSR and AODV sections are presented in detail below the most efficient protocol are:

\subsubsection{Dynamic Source Routing Protocol (DSR)}

The first was called the reactive Protocol is proposed as the goal of dynamic source routing protocol which was MANET routing system network of 200 mobile nodes, of which size imposes high with mobility [11]. Compare to disable unicast responses to other routing protocols, such as dynamic source routing protocol does not use the routing table on the concept. Routing tables, The source of the routing options instead of DSR that transmit packets on the mobile node's route cache and the full list of IP addresses in the destination node path MANET network stores to identify. After the basic work of DSR Protocol

\section{DSR basic process:}

(1) Way packets if the source node has routing request here: the discovery route cache does not find a way to find out the destination of the route is used. MANET is broadcasted throughout the route request packets. While intermediate mobile nodes from the source to the destination using the traversing packets, each intermediate nodes that routes requests to add its own IP address in the IP packet list. Thus when the destination node receives the packet, Request packet from the source all the way also known as destination path accumulation that occurs. The source node to the destination node to receive packets from the response packet to the destination route discovery mechanism to restart the route back to the transfer again. The source route request packet to send North route in reverse order packets can use recorded. After the discovery of the mechanism at the end of the route in this approach, [10] to the destination from the source is both the source and destination node full root node.

(2) road maintenance: the DSR Protocol, there is no concept Hello message which is periodically updated as such are like dynamic routing protocols as well as in AODV protocol. But everyone in the mobile network node from the source to the destination node and the next hop in the routing protocol is responsible for maintenance. The MAC layer or software is detected by specific which DSR acknowledgement. Lost in any link between Source route error packet special root paths, and informed by the source node route discovery mechanism used to restart. Most of the route in DSR cache is used for the same purpose. En route to the routing cache routing overhead is much lower than in pursuance of the concept:

(1) If the intermediate node paths from the source to the destination or the destination of the route encounters route discovery phase, while the routing cache node automatically routes replies reply with packets and then route from the source to the destination send at the same time.

(2) DSR multi paths is based on the concept thus if any link break and receives a route error packet source, so it is available in the source route alternative routes can make use of the cache, resulting in low overhead routing.

(3) If any intermediate route from source to destination path breaking next hop link that detects in its route cache intermediate route towards another route is available if that in such a case can it directly in the salvaging of the destination of the packet, the packet is forwarded to the same route used. The next section presents the AODV.

\subsubsection{AODV: Ad hoc On-Demand Distance Vector Routing Protocol}

This is one more ad hoc routing protocol which is somewhat different from the DSR protocol in working and has the following procedure to follow:

(1) Route discovery: in this case, routing cache mechanism not applicable rather source node uses the routing tables. If the source node not gets the route in the routing table towards the destination, then it can start broadcasting the RREQ packets all over the MANET network. Route Request packets usage the search engine technique. Node starts creating the reverse routing entry in routing table such that route path reach to the destination, once that node receive the route request packet. After that, the intermediate node or the destination node acknowledge route request RREQ packet by route reply RREP unicast packet and on the receipt of route reply packet, similar to the route request packet, reverse routing entry towards the source of route reply packet is also created [11] [12]. At the same time one more list is created which is called as precursor list is created which is associated with the all the routing entries.

(2) Route maintenance: All the nodes which are along with active route start broadcasting the HELLO messages periodically to all its neighbors in MANET. During this period, if any node doesn't get any kind of packet of HELLO message, then it is considered as link broken between that node and its neighbor node. Here also the REER packet is used to indicate the source about the link breakage or link failure. Sometimes local route mechanism is also used to repair the link between the source and destination mobile nodes, or else the route error packet for the same [11] [12].

Finally in this section, following table gives the comparison $n$ between the source node and destination node characteristics such as source route, destination paths, detection of neighbors etc.

\subsubsection{Comparison of Reactive Routing Protocols}

Following table 2 is showing the comparative study for above discussed three reactive routing protocols:

Table 2: Comparative Study of Reactive Routing Protocols

\begin{tabular}{|l|l|l|}
\hline Source route & DSR & YODV \\
\hline $\begin{array}{l}\text { Neighbor } \\
\text { detection }\end{array}$ & No & $\begin{array}{l}\text { Hello messages } \\
\text { (along active } \\
\text { routes) }\end{array}$ \\
\hline Route storage & Route cache & Routing table \\
\hline $\begin{array}{l}\text { Loop freedom } \\
\text { maintenance }\end{array}$ & Source route & Sequence number \\
\hline Multiple paths & Yes & No \\
\hline $\begin{array}{l}\text { Multicast } \\
\text { capability }\end{array}$ & $\begin{array}{l}\text { No } \\
\text { packet salvage/ } \\
\text { Choose another } \\
\text { route, route } \\
\text { rediscovery }\end{array}$ & $\begin{array}{l}\text { Send RERR, local } \\
\text { repair/ Route } \\
\text { rediscovery } \\
\text { maintenance }\end{array}$ \\
\hline
\end{tabular}




\subsection{Hybrid Unicast Routing Protocols}

In above points discussed the two types of routing protocols in the MANET with advantages and disadvantages of using them. To combine the advantages of proactive routing algorithms and reactive routing protocols, one more category came in place which is called Hybrid Unicast Routing Protocols which is combining the advantages of both. The most famous and hybrid protocol is Zone Routing Protocol means ZRP which is described in the following section.

\subsubsection{ZRP: Zone Routing Protocol}

ZRP (Zone Routing Protocol) is nothing but the one kind of framework for the hybrid routing protocols and which is consists of different modules such as:

(1) Intrazone routing protocol- This protocol is adopted from the proactive routing protocols which is used to maintain only the local topology. This protocol works in the within the specified zone only.

(2) Interzone routing protocol: On the other hand, this is the protocol which is adopted from the reactive protocol which is used when the route between the different zones is needed for the communication in between the source and destination.

(3) Border cast resolution protocol: This is also one more module of the ZRP which provides the most efficient broadcast technique. This protocol minimizes the redundant forwarding quantity in the case of route discovery.

\section{Advantages of ZRP}

(1) As the intrazone routing protocol is adopted from the proactive protocol, routes which are directed towards the destination within the zone are available before their demand within the zone. This is resulted into the reduced route discovery and delay reduced.

(2) The change in link status which is at one end of the MANET network is not affects the network at other end because of the fact topology information periodic broadcasting within the network zone [10].

(3) One more advantage of ZRP is that the routes between the different zones is created depending on the current requirement which ultimately saves the overhead that is required for the periodic broadcasting of the topology information throughout the MANET network.

(4) As the intrazone routing protocol is adopted from the proactive routing protocol, route maintenance of the interzone routing protocol which is based on the reactive routing protocol. By using the local topology information, the link which is broken is bypassed and thus within the zone only route optimization can be obtained.

(5) Using the local topology information in the intrazone routing protocol, efficient forwarding of the broadcast packets. This resulted into the advantage is that it can help to transmits the packet from the network covered area to the network uncovered area.

In the zone routing protocol different routing zones in the network has different radius, as the radius is the configurable parameter of zone routing protocol. Depending on the radius of the zones, the performance of the ZRP depends as properly configured radius of the zone will resulted into the better performances [10].

\subsection{Comparison of Unicast Routing Protocols}

For the comparative analysis of all three types of unicast routing protocols have considered AODV, DSR, FSR and ZRP. In table 3 presenting the comparative analysis for these protocols. Table 4 is showing the comparison between the proactive, reactive and hybrid routing protocols.

\section{SUMMARY}

Below are discussing the advantages and disadvantages of the protocols which is studied previously such as FSR, AODV, DSR and ZRP protocols

\section{1) FSR}

\section{Advantages of FSR}

- The main advantage of this routing protocol is that it can significantly reduce the consumption of the bandwidth because here the periodic link state packets are needed only in between the neighboring nodes.

- Due to the different types of frequencies of updates in between the different scopes nodes, overhead of the routing is also reduced.

- Size of the messages gets reduced by the FSR by removing the topology information from the message.

\section{Disadvantage of FSR}

Very poor performance in the MANET networks with small sizes.

Table 3: comparison between the AODV, DSR, FSR and ZRP protocols

\begin{tabular}{|l|l|l|l|l|}
\hline & AODV & DSR & FSR & ZRP \\
\hline $\begin{array}{l}\text { Network } \\
\text { organization }\end{array}$ & Flat & Flat & $\begin{array}{l}\text { Hierarchi } \\
\text { cal }\end{array}$ & $\begin{array}{l}\text { Hierarchi } \\
\text { cal }\end{array}$ \\
\hline $\begin{array}{l}\text { Neighbor } \\
\text { Detection }\end{array}$ & $\begin{array}{l}\text { HELLO } \\
\text { Messag } \\
\text { es }\end{array}$ & No & $\begin{array}{l}\text { Periodic } \\
\text { Link state } \\
\text { updates }\end{array}$ & $\begin{array}{l}\text { Periodic } \\
\text { updates } \\
\text { and } \\
\text { messages } \\
\text { as well. }\end{array}$ \\
\hline Scope & $\begin{array}{l}\text { LIMIT } \\
\text { ED } \\
\text { MANE } \\
\text { TS }\end{array}$ & $\begin{array}{l}\text { Limited } \\
\text { MANE } \\
\text { TS }\end{array}$ & $\begin{array}{l}\text { Large } \\
\text { Scale } \\
\text { MANET } \\
\text { S }\end{array}$ & Medium \\
\hline $\begin{array}{l}\text { Communicat } \\
\text { ion overhead }\end{array}$ & Low & Low & High & Medium \\
\hline
\end{tabular}

Table 4: Characteristics comparison of Proactive, Reactive and Hybrid Routing Protocols

\begin{tabular}{|l|l|l|l|}
\hline & Proactive & Reactive & Hybrid \\
\hline $\begin{array}{l}\text { Network } \\
\text { organization }\end{array}$ & $\begin{array}{l}\text { Flat/Hierarchic } \\
\text { al }\end{array}$ & Flat & $\begin{array}{l}\text { Hierarchic } \\
\text { al }\end{array}$ \\
\hline $\begin{array}{l}\text { Topology } \\
\text { dissemination }\end{array}$ & Periodical & $\begin{array}{l}\text { On- } \\
\text { demand }\end{array}$ & Both \\
\hline Route latency & Always & $\begin{array}{l}\text { Available } \\
\text { when }\end{array}$ & Both \\
\hline
\end{tabular}




\begin{tabular}{|l|l|l|l|}
\hline & available & needed & \\
\hline $\begin{array}{l}\text { Mobility } \\
\text { handling }\end{array}$ & $\begin{array}{l}\text { Periodical } \\
\text { updates }\end{array}$ & $\begin{array}{l}\text { Route } \\
\text { maintenan } \\
\text { ce }\end{array}$ & Both \\
\hline $\begin{array}{l}\text { Communicati } \\
\text { on overhead }\end{array}$ & High & Low & Medium \\
\hline
\end{tabular}

2) DSR (Reactive Routing Protocol)

Advantages and Disadvantages of DSR

- As this protocol comes into the category of the reactive routing protocol, it reduces the need flooding the MANET network with the periodic table update messages as compared to the proactive routing protocols like DSDV.

- In this protocol as the rule of reactive routing protocol, routes are created only when they are required means totally on demand; hence extra overhead which required in the proactive routing protocols is eliminated.

- The mechanism of route cache is significantly reduces the network control overhead because the intermediate nodes make proper use of route cache.

- The major disadvantage of using this DSR protocol is that broken link is does not locally repaired by the route maintenance mechanism of the DSR protocol.

- While reconstructing the route from source to the destination node, the information related to the stale route cache is gets in inconsistencies.

- Delay in the connection establishment in DSR is more as compared to the proactive protocols.

- Even though the protocol performs well in static and low-mobility environments, the performance degrades rapidly with increasing mobility. Also, considerable routing overhead is involved due to the source-routing mechanism employed in DSR. This routing overhead is directly proportional to the path length.

3) AODV (Reactive Routing Protocol)

\section{$\circ \quad$ Advantages and Disadvantages of} AODV

- Route in the protocol are created totally on demand basis.

- The mechanism of the destination sequence number is used to get fastest and recent route towards the destination.

- Network setup doesn't take too much time as compare to proactive routing protocols.

- This is most average efficient protocol in the MANET network.

- This protocol is caused by the steal route problem most of time which is the major disadvantage of this routing protocol. This happens because of the inconsistent state routes which is because of intermediate node uses the source sequence node which is old one which makes the steal route entries.

- Route Reply packets increase the load heavily because in response to the one RREQ packet so many Route Reply Packets RREP generated.

- Bandwidth consumption increases sometimes.

4) ZRP (Hybrid Routing Protocol)

\section{Advantages and Disadvantages of ZRP}

The main advantage of this protocol is that it adopts the functionality of both proactive and reactive protocols.

- This protocol provides the scalability as compared to reactive routing protocols.

- Congestion is reduced at most due to fact that the hierarchies are not used.

In the previous section as well here discussed the advantages of the ZRP protocol which is actually the combination of the advantages of the two kinds of routing protocols such proactive and reactive routing protocols.

\section{CONCLUSION AND FUTURE WORK}

In this paper have a discussed over the MANET routing protocols, investigate their characteristics and presented comparative study over the same. Basically focused on three major categories of MANET routing protocols such as proactive, reactive and hybrid routing protocols. Here discussed the different protocols under these categories with their advantages and disadvantages. Related to routing, MANET is still facing many research challenges. Every routing protocol in MANET having unique features and advantages, and hence depending on the network conditions needs to use suitable MANET routing protocol. Security is also one of the main challenges of MANET routing protocol. There are many secured routing protocols presented still they are suffered from limitations. For the further work, here suggest to present routing performance of all categories of routing protocol under the different network conditions and then based on it choose which protocol is best suit for MANET routing in an average under all networking conditions. For our research, presented new protocol for load balancing in MANET by modifying existing AODV routing protocol. Further suggesting improving the same protocol by using unique features.

\section{REFERENCES}

[1] C K Toh, Ad Hoc Mobile Wireless Networks, Prentice Hall Publishers, 2002.

[2] Robinpreet Kaur \& Mritunjay Kumar Rai, A Novel Review on Routing Protocols in MANETs, Undergraduate Academic Research Journal (UARJ), ISSN : 2278 - 1129, Volume-1, Issue-1, 2012.

[3] Tarek Sheltami and Hussein Mouftah "Comparative study of on demand and Cluster Based Routing protocols in MANETs", IEEE conference, pp. 291-295, 2003.

[4] Elizabeth M. Royer"A Review of Current Routing Protocols for Ad Hoc Mobile Wireless Networks" University of California, Santa Barbara Chai-Keong Toh, Georgia Institute of Technology, IEEE Personal Communications, pp. 46-55, April 1999. 
[5] Krishna Gorantala, "Routing Protocols in Mobile Ad-hoc Networks", A Master' thesis in computer science, pp-136,2006

[6] Abdellah Jameli, Najib Naja and Driss El Ouadgiri "Comparative Analysis of Ad Hoc Networks Routing Protocols For Multimedia Streaming”, IEEE, 1999.

[7] Shakkeera "Optimal path selection technique for Flooding in Link State Routing Protocol Using Forwarding Mechanisms in MANET".

[8] Zygmunt J. Haas, senior member IEEE and Marc R. Pearlman, member, IEEE "The performance of query control schemes for the zone routing protocol" ieee/acm transactions on networking, vol. 9, no. 4, august 2001

[9] Nicklas Beijar "Zone routing protocol" Networking Laboratory, Helsinki University of Technology, P.O. Box 3000, FIN-02015 HUT, Finland.

[10] Ammar Odeh, Eman AbdelFattah and Muneer Alshowkan, Performance Evaluation Of AODV And DSR Routing Protocols In Manet Networks, International Journal of Distributed and Parallel Systems (IJDPS) Vol.3, No.4, July 2012.

[11] Mina Vajed Khiavi, Shahram Jamali, Sajjad Jahanbakhsh Gudakahriz, Performance Comparison of AODV, DSDV, DSR and TORA Routing Protocols in MANETs, International Research Journal of Applied and Basic Sciences. Vol., 3 (7), 1429-1436, 2012 ISSN 2251-838X (C)2012 Victor Quest Publications.
[12] Sachin Dnyandeo Ubarhande, Performance Evolution of $A O D V$ and DSR Routing Protocols in MANET Using NS2, International Journal of Scientific \& Engineering Research Volume 3, Issue 5, May-2012, ISSN 22295518 .

\section{AUTHOR PROFILE}

Mahdi Abdulkader Salem He is presently doing Ph.D. in computer science and IT from SHIATS Institute, Allahabad, India, he has received his M.Tech degrees in computer science and information technology from at Sam Higginbottom Institute of Agriculture, Technology and Sciences (SHIATS), Allahabad, India in year 2012. And B.tech in computer technology in the year 2001 from Sabha Institute, Libya.

Raghav Yadav He is presently an assistant professor at Sam Higginbottom Institute of Agriculture, Technology and Sciences (SHIATS), Allahabad, India ,he is received the $\mathrm{Ph} . \mathrm{D}$. degree from the Motilal Nehru National Institute of Technology (MNNIT), Allahabad, India. He received his M.Tech. Degree in computer science and engineering from MNNIT, Allahabad. And B.E. degree in electronics engineering from Nagpur University Dr. Yadav has authored more than 15 research papers in national/international conferences and refereed journals. His research interests are in the field of optical network survivability, ad-hoc networks, and fault tolerance systems. 